\title{
Var manglende forståelse av tobakksepidemiens dynamikk en årsak til forsinket tobakksprevensjon?
}

\author{
Karl Erik Lund \\ Den Norske Kreftforening/Institutt for medisinske atferdsfag \\ Universitetet i Oslo, Postboks 1111, Blindern, 0317 Oslo
}

\begin{abstract}
SAMMENDRAG
Mens tobakksmotstanden i Norge i første halvdel av det 20. århundre mest var tuftet på moral med utgangspunkt i et religiøst paradigme, kom det i løpet av perioden 1955-61 undersøkelser som ga det tobakksforebyggende arbeidet et sekulært vitenskapsbasert fundament. Den medisinske profesjon var imidlertid noe forbeholden til at tobakk kunne representere en alvorlig trusel mot folkehelsen. Den avmålte og reserverte holdningen som først ble inntatt av legestanden må bli forstått i lys av manglende kvalitet på de tidligste epidemiologiske undersøkelsene, at legestanden på 1950-tallet selv hadde en meget høy andel røykere, og at mange leger - som høyt utdannende og derfor ofte fordomsfrie mennesker - ønsket å distansere seg fra de religiøse avholdsmoralistene som lenge hadde ledet det tobakksforebyggende arbeidet på et ikke-medisinsk grunnlag. Også fraværet av en dypere innsikt i tobakksepidemiens egentlige natur (konfigurasjon) kunne være en årsak. Det spesielle tidsforholdet mellom eksposisjon og sykdomsutbrudd i epidemiens dynamikk - ofte kalt "delay-problemet" - var egnet til å forvirre legene og helsemyndighetene. For å forstå årsakene til datidens forvirring vil det bli presentert en figur som viser ulike tidsvinduer i tobakksepidemiens forløp slik de blir skissert av Verdens helseorganisasjon.
\end{abstract}

Lund KE. Was a lack of understanding of the dynamics of the tobacco epidemic a reason for delayed tobacco prevention? Nor J Epidemiol 1995; 5 (2): 107-113.

\section{ENGLISH SUMMARY}

In the first half of the 20th century, the work against tobacco in Norway was based mainly on ethics and a religious paradigm. During the years 1955-61 several major epidemiological studies were published which provided a secular and scientific basis for tobacco prevention. However, the medical profession seemed to be sceptical about the claims that tobacco represented an important hazard to public health. The formal and reserved attitudes of the doctors should be viewed in the light of the allegedly poor scientific quality of the first epidemiological studies, the very high prevalence of smokers among doctors themselves in the 1950's, and the fact that many doctors - being highly educated and therefore often unprejudiced people - wished to distance themselves from the religious and fanatic anti-tobacco fighters. A fourth cause, which is focused in this article, may have been misinterpretation of the dynamics of the tobacco epidemic. The rather unusual relationship between exposure and disease in the tobacco epidemic - often called the delay problem - was liable to create confusion among doctors and health authorities. To help understand the medical profession's state of confusion about the size of the tobacco and health problem, a figure will be presented demonstrating the different phases of the tobacco epidemic.

\section{DE FØRSTE UNDERSØKELSER OM RØYKINGENS HELSEEFFEKT}

I en, etter dagens standard, primitiv epidemiologisk undersøkelse, rapporterte Lombard og Doring (1) i 1928 at røyking var vanlig blant kreftpasienter. Ti år seinere mente Pearl (2), etter å ha studert mortalitet for røykere og røykfrie, at det fantes et observasjonsmessig grunnlag for å hevde at røykere hadde kortere forventet levealder. Også tyskerne Muller (3) og Schairer \& Schöniger (4) hadde funnet at lungekreft forekom hyppigere blant røykere enn blant de røykfrie. Hva mekanismen kunne være ble imidlertid ikke diskutert i noen av disse undersøkelsene.

Fra rundt 400 årlige rapporterte dødsfall av lungekreft ved århundreskiftet, økte sykdommen i USA til rundt 4000 tilfeller i 1935 , ca. 11000 i 1945 til om lag 36000 i 1960 (5). Det ble lansert flere teorier om hva denne økningen kunne skyldes; bedre rapporteringsmetoder, mer sofistikerte metoder for diagnostisering som f.eks. økt bruk av røntgenundersøkelser, bedret evne til å gjøre patologiske analyser o.l. Andre 
hevdet at økningen i forventet levealder tillot utbruddet av en sykdom som i tidligere tider ikke hadde fått sjansen til å utvikle seg fordi dens potensielle ofre allerede hadde dødd av andre sykdommer. Atter andre pekte imidlertid på en av de mest dramatiske atferdsendringer i amerikansk forbrukskultur; økningen i sigarettrøykingen.

Tilhengerne av den siste teorien begynte fra 1950årene å intensivere, systematisere og evaluere forskningen om årsakssammenheng og samvariasjon mellom sigarettrøyking og lungekreft. Resultater fra dyreforsøk, kliniske og patologiske undersøkelser, og etter hvert fra prospektive og retrospektive befolkningsstudier ble gjennomgått. I retrospektive undersøkelser ble mennesker med lungekreft intervjuet om sine tidligere røykevaner. Resultatene ble deretter sammenlignet med kontrollgrupper. Disse studiene viste at røykere hadde høyere risiko for å utvikle lungekreft enn ikke-røykere, men kritikerne trakk metoden i tvil. Bl.a. ble det hevdet at lungekreftpasienter nettopp på grunn av sin sykdom kunne ha et motiv for å overdrive sitt sigarettkonsum. I prospektive studier ble grupper av individer fulgt over tid og data samlet inn på flere tidspunkter. Store utvalg gjorde det mulig å konstruere befolkningsgrupper som var identiske med unntak av sine røykevaner. Gruppene ble så sammenlignet med hensyn på utvikling av lungekreft. Forskerne fant at lungekreft oppsto mellom 3 og 9 ganger oftere blant røykerne. De som røykte relativt mye utviklet lungekreft 5 til 16 ganger oftere enn de røykfrie. Undersøkelsene viste i tillegg at røykerene også hadde høyere relativ risiko for å utvikle hjerte-kar-sykdommer.

I ettertid er det rimelig å betrakte undersøkelsene til britene Doll og Hill $(6,7)$ og nord-amerikanerne Wynder og Graham (8), Hammond \& Horn $(9,10)$, Dorn (11), Dunn, Linden \& Breslow (12) og Best, Josie \& Walker (13) som milepeler i overgangen fra mistanker til sikker viten om tobakkens skadeeffekt ${ }^{1}$. Disse forskerne anvendte epidemiologiske metoder og statistiske frekvensmål (f.eks. relativ risiko) som tidligere bare hadde blitt brukt i studier av infeksiøse sykdommer. Tilveksten av stadig nye epidemiologiske undersøkelser ga det populærvitenskapelige Reader's Digest anledning til å underholde sine lesere med en bemerkning som fortsatt siteres i røykevaneforskningen: "It is now proved beyond doubt that smoking is one of the leading causes of statistics" (14).

${ }^{1}$ Wynder \& Graham (8): retrospektiv undersøkelse av 605 amerikanske menn med lungekreft.

Doll \& Hill $(6,7)$ : prospektiv undersøkelse av 41000 britiske leger.

Hammond \& Horn $(9,10)$ : prospektiv undersøkelse av 188000 hvite amerikanere i 9 stater.

Dorn (11): prospektiv undersøkelse av 249000 mannlige amerikanske forsikringstagere.

Dunn, Linden \& Breslow (12): prospektiv undersøkelse av 67700 menn fra California

Best, Josie \& Walker (13): prospektiv undersøkelse av 78 000 kanadiske menn.

\section{LEGESTANDEN VAR FORBEHOLDEN I TROEN PÅ TOBAKK SOM EN ALVORLIG RISIKOFAKTOR}

Hvordan reagerte så den norske legestanden på de nye forskningsbaserte opplysningene om tobakkens helsenedsettende effekter? Ved å studere omtaler om tobakk i Tidsskrift for Den Norske Lageforening i perioden 1950-1965, går det fram at legestanden i lang tid forholdt seg kritisk vurderende og forbeholden (Lund KE. Samfunnsskapte endringer $i$ nordmenns tobakksatferd i det 20. århundre. Avhandling levert for dr.polit-graden, Institutt for sosiologi, Universitetet i Oslo). Følgene av tobakkseksposisjon hadde flere trekk ved seg som forvirret legene; det tok veldig lang tid før sykdommen oppsto, alle eksponerte fikk ikke sykdommen - faktisk bare et mindretall - og en hel rekke mulige "confounders" gjorde det vanskelig å trekke slutninger om kausalitet. På lederhold ble det i Tidsskrift for Den Norske Lægeforening understreket at internasjonalt anerkjente epidemiologer hadde ment at forholdet røyking - lungekreft kun var statistisk (merely statistical), og at tobakksforskerne ikke hadde skjelnet mellom korrelasjon og kausalitet. En kunne fortsatt ikke se bort fra at den samme genetiske predisposisjon både førte til opptak av sigaretter og større følsomhet overfor visse sykdommer som f.eks. lungekreft. I USA hadde faktisk enkelte lansert konspirasjonteorier om at den skjulte hensikt bak forskningen omkring tobakkens skadevirkninger egentlig var å trekke oppmerksomheten bort fra strålingsfaren og skyve den over på røykingen.

I et nummer av Lægeforeningens Tidsskrift fra 1954 ble spørsmålet stillet på lederplass, "Er det bevist at sigarettrøyking fremkaller lungekreft?" (15). Lederen omtalte de ovennevnte unders $ø$ kelsene til Wynder \& Graham (8) og Doll \& Hill $(6,7)$, og slo for det første fast at de fleste medisinere nå synes å være enige om at økningen i lungekreft de siste decennier hadde vært reell. For det andre listes mulige årsaksfaktorer opp; ettervirkninger fra en omfattende influensaepidemi som hadde herjet i 1918-19 (spanskesyken), atmosfæriske forurensninger fra fabrikkpiper etc., tjæreholdig støv fra asfalterte veier og sigarettrøyking. Lederen la deretter fram en del forhold ved sigarettrøykingen som kompliserte dens sammenheng med lungekreft. Det ble pekt på at USA hadde en mortalitet av lungekreft som var $50 \%$ mindre enn den i England til tross for et høyere sigarettkonsum. Videre ble det stillet spørsmål ved sigaretter som etiologisk faktor så lenge det ennå ikke var påvist noe carcinogent (kreftframkallende) stoff $\mathrm{i}$ røyken. Kunne ikke like gjerne lungekreft ha sammenheng med bruken av fyrstikker?

Lederen tippet likevel mot den oppfatning at sigarettrøykingen var et viktig etiologisk moment $i$ utviklingen av lungekreft, men understreket at det også måtte eksistere andre carcinogene stoffer ved 
siden av. Rådet som gis til legene er at de burde avstå fra å gi uttalelser til publikum og presse som kunne tolkes dithen at det nå forelå godtatte konklusjoner om lungekreftens årsaksforhold. Behovet for ytterligere forskning blir framhevet.

Den avmålte og reserverte holdningen som først ble inntatt av den medisinske profesjon må bli forstått i lys av særlig fire forhold:

1. en manglende kvalitet på de tidligste epidemiologiske undersøkelsene

2. at legestanden på 1950-tallet selv hadde en meget høy andel røykere - faktisk høyere enn i den øvrige befolkningen (16)

3. at mange leger - som høyt utdannende og derfor ofte fordomsfrie og sekulariserte mennesker ønsket å distansere seg fra de religiøse avholdsmoralistene som lenge hadde angrepet tobakksbruk på et ikke-vitenskapelig grunnlag

4. at tobakksepidemien på 1950-tallet befant seg i et tidsvindu hvor man lett kunne trekke gale konklusjoner om omfanget av tobakksskadene pga. en manglende forståelse av tobakksepidemiens dynamikk

Uten å ta stilling til noen rangering av disse årsakene etter viktighet, skal artikkelen i det videre rette fokus mot punkt 4 .

\section{EN MODELL AV TOBAKKSEPIDEMIENS DYNAMIKK}

Årsaken til den manglende forståelse av epidemiens dynamikk blir ofte kalt "delay-problemet" og har å gjøre med det spesielle tidsforholdet mellom eksposisjon og sykdomsutbrudd. For å forstå årsakene til datidens forvirring, er det hensiktsmessig å ta utgangspunkt i figur 1, som viser en deskriptiv modell for sekvensene i sigarettepidemien fra Verdens helseorganisasjon (17).

I tillegg til at modellen opplyser om røykingens spredningsform og -hastighet, inneholder den også beskrivelser av forløpet til de røykerelaterte sykdommene og vurderinger av muligheter til forebygging på hvert stadium. Modellen omfatter m.a.o. både en atferds- eller eksposisjonskomponent (røyking) og en sykdomskomponent. Mønsteret i modellen illustrerer at sykdomsomfanget $i$ befolkningen ikke inntreffer simultant med atferdskomponenten. Et forutgående atferdsmønster - røykingen - nedfeller seg først i en sykdomsepidemi etter flere tiår. På samme måte som innslaget av røyke-attribuerte dødsfall i en befolkning er sterkere relatert til det forhenværende og tilbakelagte tobakksforbruket enn til samtidens konsum, vil altså utbredelsesmønsteret av røyking i vår tid komme til å få sitt parallelle motstykke i tobakksrelatert sykelighet og dødelighet om noen tiår. Basert på nærmere 100 års observasjon av de land som har lengst historie på omfattende tobakksbruk, bl.a. USA, Canada og Storbritannia, inndeler Verdens helseorganisasjon sigarettepidemien i 4 faser som hver gis følgende karakteristikk:

\section{1. fase}

Epidemiens begynnerfase har en varighet på 10-20 år. Omlag $15 \%$ av mennene røyker, mens andel røykere blant kvinner ikke overstiger 5\%. Forbruket pr. voksen innbygger ligger på rundt 500 gram. Tobakksrelaterte dødsfall er foreløpig fraværende. Tobakksforebyggende tiltak er ikke igangsatt. Helseopplysningsarbeidet preges av ernæringskunnskap og planer

\section{Figur 1 \\ Verdens helseorganisasjons modell over spredningsforløpet av sigarettepidemien}

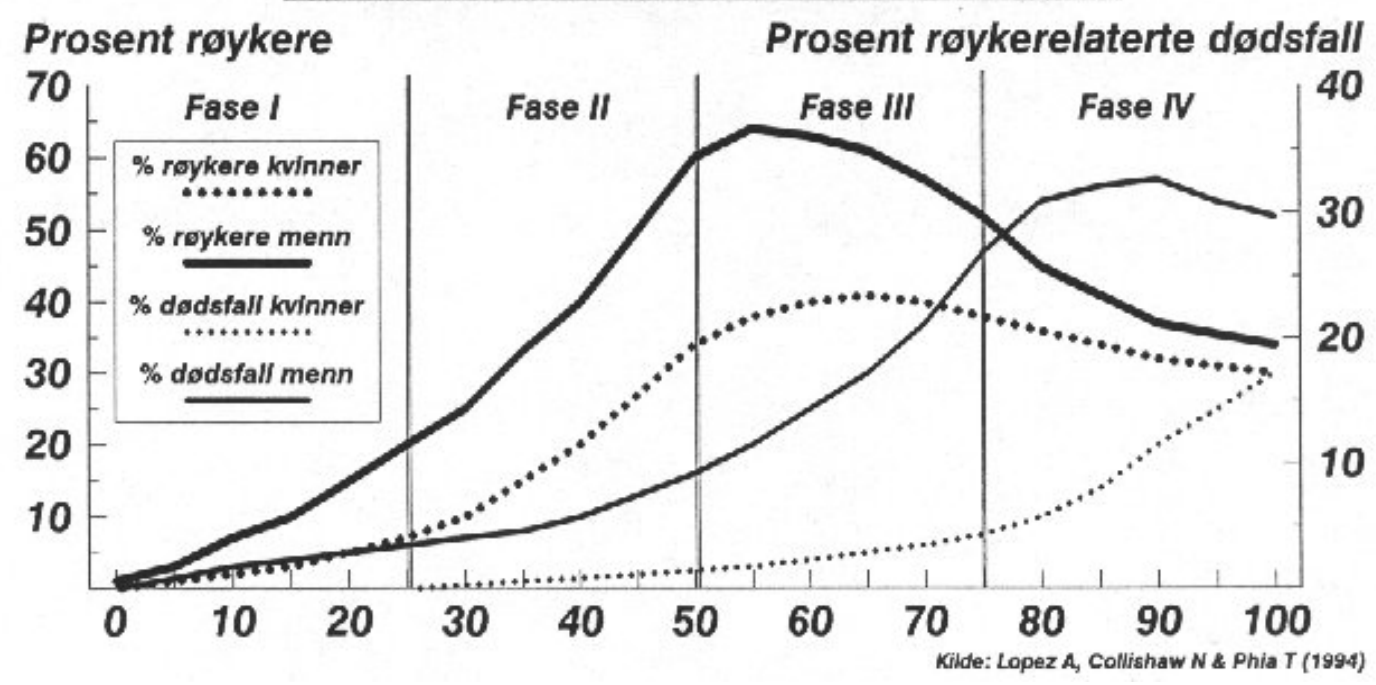


for å bekjempe infeksjonssykdommer. Andel røykere blant menn er sterkt stigende, mens sosiokulturelle normer legger sterke bånd på utbredelsen av kvinners røyking. Epidemien av tobakkssykdommer kan fortsatt forhindres for begge kjønn.

Pr. dato er mange utviklingsland, særlig i sentralAfrika, i dette stadium.

\section{2. fase}

Denne fasen har en varighet på 20-30 år. Andel røykere blant menn øker fortsatt og når i løpet av perioden opp på et toppunkt rundt 50-80\%. Andelen forhenværende røykere er foreløpig lav. Andel røykere blant kvinner stiger, men ligger betydelig lavere enn blant menn. Forbruket pr. voksen innbygger er kommet opp i 1000-3000 gram, hovedsakelig konsumert av menn. Tobakksforebyggende arbeid ligger fortsatt brakk. Opplysningsvirksomheten om tobakk er sporadisk og usystematisk og har sjelden statlig støtte. Mot slutten av denne fasen utgjør de tobakksrelaterte dødsfall omkring $10 \%$ blant menn, men fortsatt dør svært få kvinner av sykdommer som skyldes røyking. Insidensraten av lungekreft har i løpet av perioden steget fra 5/100 000 til 50/100 000 for menn. Tobakkssykdommene kan fortsatt forhindres for kvinner.

Land som Japan, Kina og en del andre land i Asia, Latin-Amerika og det nordlige Afrika befinner seg for tiden i dette stadium.

\section{3. fase}

Den tredje fasen varer omkring 30 år. Prevalensen av røykere blant menn synker. Mot slutten av perioden kryper den ned mot 40\%. Andel forhenværende røykere i befolkningen stiger, særlig blant eldre menn. Innslaget av røykere blant kvinner har nådd et stabilt platå på $35-40 \%$. Dette platået ligger betydelig lavere enn toppunktet for andel røykere blant menn, men varigheten på kvinners toppnivå er betydelig lengre. Sammensetningen av røykere blant kvinner kjennetegnes av en markant aldersgradient idet få eldre røyker. I løpet av denne perioden stiger det gjennomsnittlige antall sigaretter pr. røyker - færre røykere forbruker flere sigaretter. Det er en sterk vekst i de røykerelaterte sykdommene. Mot slutten av perioden er røyking skyld i ca. 30\% av dødsfallene blant menn - blant middelaldrende menn er den tobakksrelaterte mortaliteten enda høyere. Fortsatt er det bare omlag $5 \%$ av dødsfallene blant kvinner som skyldes røyking, men dette tallet er stigende. Insidensraten av lungekreft har nådd 110-120/100 000 for menn og 25-30/100 000 for kvinner. I løpet av perioden etableres det politisk vilje til tobakksforebyggende tiltak. Staten engasjerer seg i tobakksspørsmålet. Opplysning på skolene systematiseres. Media spiller en nøkkelrolle for å skape et negativt tobakksetos $\mathrm{i}$ befolkningen. Dette åpner opp for en ytterligere utbygging av tobakksprevensjonen. Befolkningen aksepterer avgiftsøkninger og reklamerestriksjoner. Den sosiale og kulturelle glamor som heftet ved røykingen i tidligere faser, er i ferd med å bli dekonstruert. Epidemien av tobakkssykdommer er kun reversibel for kvinner.

For tiden er det land i Sør- og Øst-Europa som kan karakteriseres med disse kjennetegn.

\section{4. fase}

Innslaget av røykere blant menn er nå redusert til kvinnens nivå, og nedgangen fortsetter nå parallelt for begge kjønn. I noen år vil andelen røykende kvinner overstige mennenes andel, men forskjellen vil være liten. Andelen røykerelaterte dødsfall for menn når sitt toppnivå tidlig i denne fasen og er skyld i 30-35\% av all død. Blant middelaldrende utgjør disse dødsfallene 40-45\%. Insidensraten av lungekreft blant menn blir etter hvert fallende. Midtveis i denne fasen venter man ennå på den fulle effekten av kvinners røyking. Omkring 20 år etter at menn hadde sitt toppunkt, stiger tobakksrelatert død blant kvinner til et toppnivå på 20-25\% av all død. Det er sterke antitobakksstrømninger i befolkningen. I media er det tendenser til at røyking og røykerne avromantiseres, stupidifiseres og stigmatiseres. Kamporganisasjoner kjemper for beskyttelse mot tobakkseksposisjon. Epidemien av tobakksykdommer er ikke reversibel verken for kvinner eller menn.

Land med den lengste historie av omfattende tobakksbruk tilhører nå denne kategorien. Eksempelvis har England og USA nå vært gjennom sigarettepidemiens fire faser.

\section{DELAY-PROBLEMET SOM ÅRSAK TIL LEGENES FORBEHOLDENHET}

Da de mest framsynte epidemiologer først begynte å uttrykke bekymring for en forestående røykerelatert sykdomsutbredelse av epidemiske proposjoner, hadde sigarettrøykingen i land som USA, Canada og Storbritannia eksistert i omlag 50 år. Forskernes interesse for tobakkssykdommene inntraff m.a.o. i et tidsvindu da epidemien var i overgangen fra fase II til fase III i modellen. I dette stadium har menn sin toppnotering med 50-80\% røykere, mens røykeandelen blant kvinner er omlag $25 \%$ og stigende. Da forskerne på dette tidspunkt studerte de forutgående endringene i befolkningens tobakksatferd, så de at det hadde foregått en meget hurtig økning i prevalens av røykere de siste tiår - særlig blant menn. Denne økningen hadde passert uten at insidensen av røykesykdommer hadde steget tilsvarende. Selv om 1 av 4 kvinner røykte på dette stadium, var det likevel så og si ingen som døde av røykerelaterte sykdommer. Hvis forskerne i tillegg foretok synkrone sammenliknende analyser av dødeligheten av lungekreft mellom ulike land, ville de også finne at f.eks. USA 
ikke hadde særlig høyere insidensrate enn land hvor innslaget av røykere var langt lavere.

På 1950-tallet hadde de fleste leger fortsatt ikke etablert noen inngående forståelse av dette tidsforholdet mellom atferds- og sykdomskomponent. I ettertid kan det derfor spekuleres i om det var fraværet av innsikt i den epidemiologiske konfigurasjon som var skyld $i$ at den medisinske profesjon lenge underestimerte anslagene for de tobakksrelaterte dødsfall, med det til følge at det tobakksforebyggende arbeidet ble så fatalt forsinket.

Det var imidlertid andre grupperinger som ønsket "den nye viten" særlig velkommen. Ikke minst ble de nye medisinske rapportene godt mottatt av avholdsmoralistene og indremisjonærene som hadde dominert i Landslaget mot tobakkskadene siden opprettelsen i 1916. Disse hadde, mest på etisk grunnlag, gått i spissen for arbeidet mot tobakken i nærmere 50 år. Skadefro kunne en gammel ildsjel i tobakkskampen skulestyrar Håkon Nakling - konstatere at det også var et vitenskapelig dokumentert medisinsk grunnlag for sitt arbeid:

"Det er ei stor glede for oss som er gamle i kampen mot tobakkondet, at vi no kan ha ei kjensle av større medbør $i$ arbeidet enn for ein mannsalder eller to

sidan. Vi har alltid hatt sanninga på vår side, men

fliren og harselasen var sterke "argumenter" imot.

No skulle ein tru at desse to røystene er på og tagnar.

Tobakkspørsmålet er no vorte livsens alvor, i alle

høve for stor-røykarar. Fliren vert borte!" (18).

\section{HVILKEN FASE ER TOBAKKSEPIDEMIEN I NORGE?}

Til tross for sin noe mekaniske utforming, er epidemimodellen godt egnet som beskrivelse av et historisk hendelsesforløp. For å avgjøre hvilke faser av tobakksepidemien som er tilbakelagt og hvilke stadier som gjenstår for Norges vedkommende, kan figur 2 være oppklarende. Figur 2 viser den faktiske aldersjusterte insidensraten av lungekreft for kvinner og menn i perioden 1953-1990 (19), og en framskrivning av den samme raten til år 2010 (20). I tillegg viser figuren beregnet andel røykere for de to kjønn i perioden 1910-1994 (21).

Mønsteret for de fire linjene i figur 2 tilsvarer konturene i epidemimodellen (fig. 1). Økningen i andel røykere blant menn i den første halvpart av det 20. århundre følges av en tilsvarende vekst i lungekreftinsidens $i$ de siste 50 år. I følge figuren vil reduksjonen i prevalens røykere blant menn fra midten av århundret medføre en predikert nedgang $\mathrm{i}$ lungekrefthyppighet omtrent fra årtusenskiftet. For kvinner er bildet et annet. Det var først i 1970-årene at insidensraten av lungekreft begynte å stige. En parallell økning i andel røykere hadde foregått omtrent fra 1930.

Figur 2 indikerer at spredningsforløpet for sigarettrøyking i Norge bærer de kjennetegn som viser at fase I og II er tilbakelagte stadier. Nå, mot slutten av det 20. århundre, har tobakksepidemien også gjennomlevd det meste av fase III og er på vei inn i den - foreløpig - siste fasen. Innslaget av røykere blant menn er nå redusert til kvinnens nivå, aldersgradienten blant kvinner er på det nærmeste utlignet (22) og røykerne er sterkt sosialt deklassert (23). Dette er alle kjennetegn på at epidemien nærmer seg det fjerde stadium.

I ren etterpåklokskap kan vi nå slå fast at om effektive tobakksforebyggende tiltak hadde blitt satt $\mathrm{i}$ verk på det tidspunkt hvor de første vitenskapelige

\section{Figur 2
Kjønnsseparat insidensrate av lungekreft
1953-2010* og andel røykere 1910-1994**}

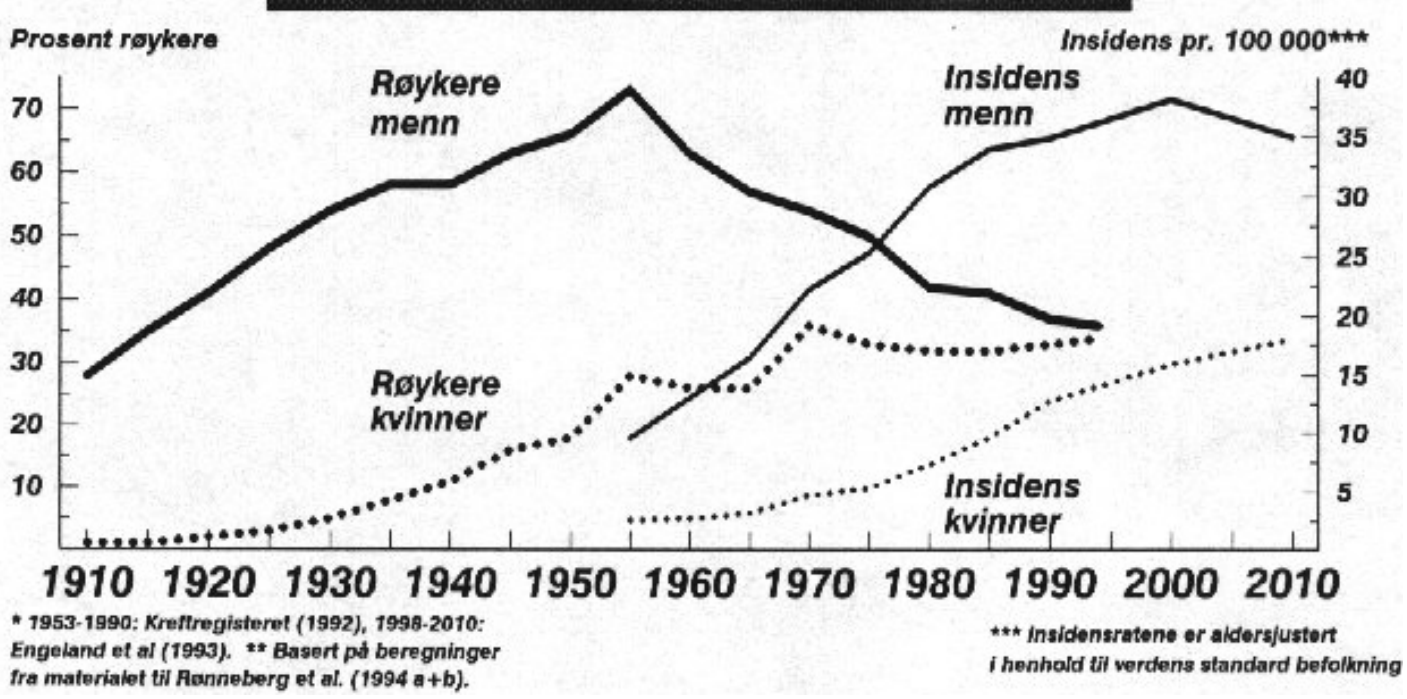


rapportene om tobakkens helsenegative virkninger kom - altså rundt 1955-60 - kunne sannsynligvis mange tusen tobakksrelaterte dødsfall vært forhindret.

\section{EPIDEMIMODELLENS NOMOTETISKE STATUS}

Som beskrivelse av et hendelsesforløp er epidemimodellen både plausibel og begripelig. Som forklaringsmåte kan modellen imidlertid kritiseres fra flere hold. Den viktigste vitenskapsteoretiske innvendingen er at modellen gjør historisk utvikling til herre over mennesket og menneskelig handling og ikke omvendt. Mønsteret i spredningsforløpet betraktes på sett og vis som en ubrytelig lov som mennesket mekanisk innretter seg etter. Med filosofen Hans Skjervheim (24) kan en si at mennesket er blitt objektivert. Teorien evner ikke å ta del i de intrapsykologiske og interpersonlige vurderinger som hele tiden foregår. Når vi som forskere objektiverer vår omverden på denne måten vil samfunnsutviklingen framtre som determinert, som om den følger ubrytelige naturlover. Menneskers følelser av å velge handlingsalternativ etter sin fri vilje vurderes m.a.o. som en illusjon.

Den posisjon som betrakter menneskers atferd på denne måten, blir i vitenskapsteorien ofte betegnet som nomotetisk. Et annet eksempel på en utviklingsmodell som også anvendes på spredningen av tobakk (25), og som utrykker slike historisk determinerte prosesser, er teorien om diffusjon av innovasjoner (26). Også vitenskapsteoretikeren Karl Popper har rettet en beslektet type kritikk mot det han betrakter som "historisisme" i samfunnsvitenskapene. Popper understreker det prinsipielt umulige $i$ at samfunnsvitenskap kan utforme langsiktige historiske profetier fordi menneskers historie påvirkes av veksten i vår kunnskap (27).

Det er nettopp kunnskapsøkningen som kan forhindre at de forløpene som epidemimodellen beskriver skal gjenta seg i de land som ennå befinner seg i den tidligste fase - altså mange av de mest folkerike land i verden. Fra et globalt helsesynspunkt vil en gjentagelse av hendelsesforløpet også i de land hvor omfanget av røykingen fortsatt ikke har nådd epidemiske proposjoner medføre en human katastrofe. Det disse land kan nyte godt av er nettopp kunnskapsøkningen om tobakkens helseskader som er etablert siden 1960-årene. De har fortsatt en gylden mulighet til å strupe epidemien ved sin fødsel. Det den medisinske ekspertise i disse nasjonene (forhåpentligvis) nå vet - og som helsemyndighetene i Norge ikke visste i 1950-årene - er at det vil være en formidabel feilvurdering å ignorere tobakk som et folkehelseproblem bare fordi dødelighetsratene av tobakksrelaterte sykdommer foreløpig er lave. I Norge kom altså denne kunnskapen så forsinket $\mathrm{i}$ epidemiens forløp at den kun ble å betrakte som en sein-fase prevensjon.

\section{REFERANSER}

1. Lombard HL, Doering CR. Cancer studies in Massachusetts. 2. Habits, characteristics and environment of individuals with and witout cancer. N Engl J Med 198 (10): 481-7, 1928.

2. Pearl R. Tobacco smoking and longevity. Science 87 (2253): 216-7, 1938.

3. Muller FH. Tabakuiss brauch und Lungencarcinoma. Zeitschr Krebsforsch 49: 57-84, 1939.

4. Schairer E, Schöniger E. Lungenkrebs und Tabakverbrauch. Zeitschr Krebsforsch 54: 261-9, 1943.

5. Patterson JT. The Dread Disease: Cancer and Modern American Culture. Cambridge, Massachusetts: Harvard University Press, 1987.

6. Doll R, Hill AB. The mortality of doctors in relation to their smoking habits. A preliminary report. $\mathrm{Br} \mathrm{Med} J$ i (4877): 1451-55, 1954.

7. Doll R, Hill AB. Lung cancer and other causes of death in relation to smoking. A second report on the mortality of British doctors. Br Med J ii: 1071-81, 1956.

8. Wynder EL, Graham EA. Tobacco Smoking as a possible etiologic factor in bronchiogenic carcinoma: A study of 648 proved cases. J Am Med Assoc 143: 329-96, 1950.

9. Hammond EC, Horn D. Smoking and death rates - Report on fortyfour months of follow up of 187783 men. I. Total mortality. J Am Med Assoc 166 (10): 1159-72, 1958.

10. Hammond EC, Horn D. Smoking and death rates - Report on fortyfour months of follow up of 187783 men. II. Death rates by cause. J Am Med Assoc 166 (11): 1294-1308, 1958.

11. Dorn HF. The mortality of smokers and nonsmokers, Proceedings of the Social Statistics Section of the American Statistical Association. Papers presented at the annual meeting of the American Statistical Association, Chicago, Illinois, Dec. 27-30, 1958. 
12. Dunn JE, Linden G, Breslow L. Lung cancer mortality experience of men in certain occupations in California. Am J Public Health 50 (10): 1475-87, 1960.

13. Best EWR, Josie GH, Walker CB. A Canadian study of mortality in relation to smoking habits. A preliminary report. Can J Public Health 52: 99-106, 1961.

14. Reader's Digest December 1961.

15. Tidsskr Nor Laegeforen 84 (17): 566-7, 1954.

16. Thürmer H, Bjartveit K, Hauknes A. Norske legers røykevaner 1952-84. Konsekvenser for pasientinformasjon. Tidsskr Nor Lageforen 106 (24): 2961-4, 1986.

17. Lopez AD, Collishaw NE, Phia T. A descriptive model of the cigarette epidemic in developed countries. Tobacco Control 3: 242-247, 1994.

18. Tobakken og Vi 2: 24, 1966.

19. Kreftregisteret. Cancer in Norway 1992. Rapport. Institutt for epidemiologisk kreftforskning, Kreftregisteret, Oslo, 1992.

20. Engeland A, Haldorsen T, Tretli S, Hakulinen T, Hörte LG, Loustarinen T, Magnus K, Schou G, Sigvaldson $\mathrm{H}$, Storm HH, Tulinius H, Vaittinen P. Predictions of cancer incidence in the Nordic countries up to the years 2000 and 2010. APMIS 101 (Suppl 38), 1993.

21. Rønneberg A, Hafstad A, Lund KE. Lifetime smoking habits among Norwegian men and women born between 1890 and 1974. Int J Epidemiol 23: 267-76, 1994.

22. Statens tobakkskaderåd. Opp i røyk. Om tobakksbruk i Norge gjennom 20 år, 1973-1993. Rapport. Statens tobakkskaderåd, Oslo, 1994.

23. Lund KE. Er røyking blitt lavstatus? Samfunnsspeilet. Tidsskrift om levekår og livsstil, Nr. 3: 3-6, 1988.

24. Skjervheim H. Deltakar og tilskodar. Skriftserie nr. 6. Institutt for sosiologi, Universitetet i Oslo, 1974.

25. Ferrence R. Deadly Fashion. The rise and fall of cigarette smoking in North America. Garland Publishing, New York, 1989.

26. Rogers E. Diffusion of Innovations. Third Edition. The Free Press/Macmillan Publishing, New York, 1983.

27. Popper K. Fornuft og rimelighet som tenkemåte. Dreyer, Oslo, 1981. 